\title{
Human Rights Approach in Promoting Rights of Vulnerable Women; the HIV Infected and Affected in Tinderet, Nandi County
}

\author{
Mr. Jack Ochieng' Nyaliech, PhD Candidate ${ }^{1}$ Dr. Thomas Otieno Juma, $\mathrm{PhD}^{2 *}$ \\ 1.School of Arts and Social Sciences; Dept. of History, Political Science, and Public Administration; Moi \\ University, Kenya \\ 2.School of Arts and Social Sciences; Dept. of Humanities; University of Kabianga, Kericho Kenya
}

\begin{abstract}
This paper sought to examine human rights approach in promoting rights of vulnerable women. HIV/AIDS infected and affected Women in Kenya right's such us autonomy, equality in relationships, security of property ownership, financial control and health care still persist. Equally, some laws have continued to deny women the right to make decisions relating to their lives, their children, their property, and their health yet women's human rights are Human Rights. This coupled with the fact that Kenya is a signatory to and has adopted applicable human rights instrument. The study focused on vulnerable women in Tinderet Sub-County, Kenya. Study adopted mixed method while using systematic sampling techniques to select 114 key informant respondents. The data collection methods included use of personal interviews, in- depth interviews, and key informant interviews. Quantitative and qualitative approaches were used in the study and for data analysis where themes, content analysis, and relevant SPSS tool were employed. The paper found that there is need to promote rights of HIV/AIDS vulnerable women through approaches such as; educating them on their rights, created forums for discussing issues affecting them, advocating their welfare, and protecting them from gender-based violence. It concluded that INGOs such as World Vision have played a significant role in promoting the rights of the vulnerable such as women through community led approaches which are easy to implement with better outcomes. Keywords: Human Rights, Human Rights Approaches, Women Rights, Rights of Vulnerable, Persons with HIV/AIDs Rights, Health Rights
\end{abstract}

DOI: $10.7176 / \mathrm{JLPG} / 99-05$

Publication date:July $31^{\text {st }} 2020$

\section{Introduction}

Human Rights approach in our thinking would be the conceptual grounding of human rights normatively to international standards and operationalizing them towards an end, in this case to promote and protect rights of vulnerable women. By so doing they increase their chance to participate in development for their good and for the community good.

To this, Yamin (2008) suggests, human rights are conceived as tools that allow people to live lives of dignity, to be free and equal citizens, to exercise meaningful choices, and to pursue their life plans. Gauri and Gloppen (2012) presents the following key elements of human rights approaches include; participation, accountability, non-discrimination, empowerment, linkages to rights, and sustainability. Importantly, we note their emphasis to inclusivity of those with rights (humans) without any bias, making effort to include those with challenges and improve them, giving feedbacks of actions, and finally being ready to make rights integral as concerned institutions.

International conventions recognize eight basic human rights: civil, political, economic, social, cultural, environmental, developmental, and sexual. All of these rights play a role in the just and humane treatment of people who, as a consequence of their vulnerability to HIV, typically are both marginalized and in need of unique services and accommodation (Aziza et.al 2009). According to Jamie and Piot (2017), more than 35 years since the HIV/AIDS pandemic began, it continues with two million new infections each year, and the call to "end of AIDS" by 2030 remains elusive. Violations of human rights continue to fuel high rates of new infections among key populations and a generalized epidemic in much of sub-Saharan Africa. Globally, in 2015 there were an estimated 36.7 million people, women make up the majority (60 per cent) of people living with HIV in subSaharan Africa, home to 7 out of every 10 people living with HIV in the world and they account for 34 per cent of people living with HIV in Europe and Central Asia(UNAID 2015). This high prevalence rate of HIV infection among women of all ages has exposed women to various vulnerabilities from cultural, economic and political fronts. It goes without saying that these patterns depicts HIV/AIDS to be more of a 'woman's disease' in reality and perception, which makes them vulnerable to regressive social, cultural and economic consequences as well as for efforts to reduce gender inequality

It is the inequalities between women and men that are driving the global HIV \& AIDS pandemic, and in turn, this pandemic is exacerbating existing gender inequalities. As Stephen Lewis illustrates, HIV \& AIDS in 
Africa has a female face, and this female face will be eradicated from Africa if we do not respond adequately (Lewis, 2007).

Barnett and Whiteside (2002), argued that HIV/AIDs has continually exposed women to great vulnerabilities and denial of fundamental human rights. From a physiological and medical perspective women are at a greater risk of getting infected. In addition, they are often solely responsible for the household and children, and have less financial and material reserves to fall back on. Women also face the risk of abandonment of abuse at the hands of their partners when HIV/AIDS strikes or when family members fall as result of HIV, it's the girls who will be removed from schools to take care of those who are sick which increases their susceptibility to poverty and to the disease because they will probably marry younger and will not have the benefits of an education.

Jonathan Mann (1999) pointed out the major societal risk factor for vulnerability to HIV is to belong to a society that is systematically undermining women. It's worth noting that before AIDS appeared, women were already discriminated against, marginalized, stigmatized and excluded from society and HIV only worsened the situation because it called into question the moral capacity of our societies the fact that it was seen as "a disease for the morally inept'”.

Kenya is among the HIV high burdened countries in Sub-Saharan region with 1.6 million people living with HIV. In 2016, women accounted for 910,000 (More than 56\%) of the 1.6 million people living with HIV in Kenya. As in many parts of sub-Saharan Africa, women in Kenya face discrimination in terms of access to education, employment, property rights, and healthcare and HIV/AIDs has worsened the situation (UNAIDS,2018).Kenyan has some of the best known human rights instrument adopted from the UN universal declaration on human rights (1945) and the African Charter on human and people's right (1981) anchored in her Chapter 4 of the 2010 constitution under the bill of rights and other subsidiary laws like HIV and AIDS prevention and control act of 2006 which are meant to safe guard the rights of women infected and affected. Indeed much has been realized as far as the protection of women rights are concerned but more need to be done.

International non-governmental organizations like World Vision have been supporting implementation of various approaches to promote the rights of women infected and affected with HIV in Kenya for sustainable development. This paper is part of a study on the contribution of World Vision to development through promoting the rights of HIV/AIDs infected women in Tinderet Sub-County in Nandi County, Kenya.

\section{Problem Statement}

Women in Kenya continue to be more disadvantaged in patriarchal systems that interfere with their daily lives (Oloo,2007).Women's rights activists (Vienna Declaration and Programme of Action, 1993) have mobilized to ensure that women's human rights were fully on the agenda of the international community under the rallying cry "Women's Rights are Human Rights." The Vienna Declaration and Programme of Action (VDPA) stated that "the human rights of women and of the girl-child are an inalienable, integral and indivisible part of universal human rights" (para. 18). This among other instruments set in place approaches to universalization of women rights in socio-eco-political contexts where health related issues such as HIV/AIDs are involved. Despite such ideals, HIV/AIDs existence has made the situation worse by providing a platform for continual abuse of women's rights. This has led in some cases; engineered lack of control on financial resources, restricted mobility, violence, limited educational opportunities, and lack of quality sexual and reproductive health services (Mumma, 2010). Kenya being a signatory and having adopted human rights instrument from the UDHR (1945) and the African Charter on human and people's right (ACHPR) (1981) anchored in Chapter 4 of the (CoK, 2010) under the bill of rights and other subsidiary laws such as HIV/AIDS Prevention and Control Act (2006) ought to have safe guarded the rights of women. Nonetheless, HIV/AIDS infected and affected Women in Kenya right's such us autonomy, equality in relationships, security of property ownership, financial control and health care still persist. Furthermore, some laws have continued to deny women the right to make decisions relating to their lives, their children, their property, and their health (UNDP, 2016). This background necessitates the study examination of Human Rights approach in promoting rights of vulnerable women (the HIV infected and affected) in Tinderet, Nandi County.

\section{Human Rights Concepts on Women}

The Universal Declaration of Human Rights adopted by the United Nations General Assembly in 1948 outlines what is considered in the last 4 decades to be the fundamental consensus on the human rights of all people in relation to such matters as security of person, slavery, torture, protection of the law, freedom of movement $\&$ speech, religion, and assembly, and rights to social security, work, health, education, culture, \& citizenship. It clearly stipulates that these human rights apply to all equally "without distinction of any kind such as race, color, sex, language... or other status" (Art.2) (Bunch \& Frost 2000).

Accordingly, Bunch (2000), the Universal Declaration of Human Rights defines human rights as universal, inalienable, and indivisible and these characteristics are gravely important for women's human rights. The 
universality of human rights means that human rights apply to every single person by virtue of their humanity and this also means that human rights apply to everyone equally, for everyone is equal in simply being human.

The indivisibility of human rights means that none of the rights that are considered to be fundamental human rights are more important than any of the others since they are inter-related. Human rights encompass civil, political, social, economic and cultural facets of human existence; the indivisibility premise highlights that the ability of people to live their lives in dignity and to exercise their human rights fully depends upon the recognition that these aspects are all interdependent. The fact that human rights are indivisible is important for women, since their civil and political rights historically have been compromised by their economic status, by social and cultural limitations placed on their activities, and by the ever present threat of violence that often constitutes an insurmountable obstacle to women's participation in public and political life. The idea of indivisibility has provided women with a common framework through which to emphasize the complexity of the challenges they face, and to highlight the necessity of including women and gender conscious perspectives in the development and implementation of policy. By calling upon the indivisibility of women's human rights, women have rejected a human rights hierarchy, which places either political or civil rights or socio-economic rights as primary. Instead, women have charged that political stability cannot be realized unless women's social and economic rights are also addressed; that sustainable development is impossible without the simultaneous respect for, and incorporation into the policy process of women's cultural and social roles in the daily reproduction of life; and that social equity cannot be generated without economic justice and women's participation in all levels of political decision-making (Morsinki,1991)

However, tradition, prejudice, social, economic and political interests have combined to exclude women from prevailing definitions of "general" human rights and to relegate women to secondary and/or "special interest" status within human rights considerations. This marginalization of women in the world of human rights has been a reflection of gender inequity in the world at large and has also had a formidable impact on women's lives. It has contributed to the perpetuation, and indeed the condoning, of women's subordinate status. It has limited the scope of what was seen as governmental responsibility, and thus has made the process of seeking redress for human rights violations disproportionately difficult for women and in many cases outright impossible(Bunch,2000).

Retrospectively, Morsinki(1991) posited that women's rights are protected under international law which some states have ratified and periodically report to bodies of experts, which issue recommendations on the steps required to meet the obligations laid out in the treaties. These treaty-monitoring bodies also provide authoritative interpretations of the treaties and, if States have agreed, they also consider individual complaints of alleged violations. Commission on Human Rights began drafting two human rights treaties, the International Covenant on Civil and Political Rights(1966) and the International Covenant on Economic, Social and Cultural Rights(1966). Together with the Universal Declaration, these make up the International Bill of Human Rights

Office of the Higher Commission on Human Rights (2014) acknowledged that a series of International conferences produced significant political and global commitments to women's human rights and equality. Starting with the 1975 International Women's Year hosted in Mexico City themed World Conference on the International Women's Year, resulted in the World Plan of Action and the designation of 1975-1985 as the United Nations Decade for Women. In 1980, international conference on women was held in Copenhagen and the Convention on the Elimination of All Forms of Discrimination against Women was opened for signature. Further, third World Conference on Women was held in Nairobi, with the Committee on the Elimination of Discrimination against Women having begun its work in 1982. These three world conferences witnessed extraordinary activism on the part of women from around the world and laid the groundwork for the world conferences in the 1990s to address women's rights, including the Fourth World Conference on Women held in Beijing in 1995. Moreover, the rights of women belonging to particular groups, such as older women, ethnic minority women or women with disabilities, have been also addressed in various other international policy documents such as the International Plans of Action on Ageing (Vienna, 1982 and Madrid, 2002), the Durban Declaration and Programme of Action (2001) and the World Programme of Action concerning Disabled Persons (1982).

Regionally, the African Charter on Human and Peoples' Rights known as Banjul declaration was adopted in 1981 by the Organization of African Unity presently African Union prohibits discrimination of women on any grounds, including sex, in the enjoyment of the rights guaranteed by the Charter. Further, it mentions the obligation of African States to "ensure the elimination of every discrimination against women and also ensure the protection of the rights of the woman and the child as stipulated in international declarations and conventions". More progressively the Maputo Protocol (2003) produced the African Charter on Human and People's Rights on the Rights of Women in Africa which remains the objective legal instruments providing a comprehensive set of human rights for African women. Unlike any other women's human rights instrument, it details wide-ranging and substantive human rights for women covering the entire spectrum of civil and political, economic, social and cultural as well as environmental rights (OHCHR, 2014) 


\section{Legal instruments in support of rights of HIV/AIDS infected Women in Kenya}

Human rights on the basis of all instruments do not segregate rights on grounds of sickness; rights remain rights as long as one is human. According to UN Commission on Human Rights Resolutions 2001/51, Governments are responsible for promoting and protecting both public health and human rights (UNCHR,2001).There are no specific international human rights treaties specifically mentioning HIV or the rights of individuals in the context of HIV/AIDS however the good news is that international human rights mechanisms responsible for monitoring government action have expressed their commitment to exploring the implications of HIV/AIDS for governmental obligations. Based on these obligations, governments can be understood as legally responsible for instituting policies and programs that can reduce the spread and impact of HIV/AIDS. HIV/AIDS policies and programs can be improved by a systematic review of how and to what extent interventions are both respectful of human rights and of benefit to public health. The questions described in the box below can be used by policymakers and public health and other government officials to aid in the development, implementation, and evaluation of more effective HIV/AIDS policies and programs; they can also be used by nongovernmental organizations and other concerned actors as an advocacy tool to hold governments accountable vis-à-vis compliance with their international legal obligations to promote and protect both public health and human rights, (UNCHR, 1998).

The Universal Declaration of Human Rights, drafted by the United Nations in 1945, inspired numerous international, regional, and subject-specific conventions, which serve as a foundation for modern international human rights law (Cook 1994). The International Covenant on Civil and Political Rights; the International Covenant on Economic, Social, and Cultural Rights; the African Charter on Human and People's Rights; and the Convention on the Elimination of All Forms of Discrimination Against Women, (1979) are a few of the legal instruments that provide a set of human rights principles that now have come to be considered as international customary law on women rights (Cook, 1994).

A UNAIDS 2016 political Declaration on Ending AIDS puts pressure on the states and non-state actors to uphold these rights of people living with, at risk of, and affected by HIV for meaningful realization of sustainable development goal three. Earlier to 2006, the UNAIDS provided an international guideline on HIV/AIDS and Human rights, a tool that provides 12 guidelines for what countries must do to fulfill their human rights commitment (UNAIDS,2016).

Kenya is among the States who have ratified part of these legal instrument to form part of her 2010 constitution particularly Chapter four which outlines socio-economic and cultural rights of citizens under the bill of rights. In 2006, Kenya adopted HIV prevention and Control act of Parliament to provide measures for the prevention, management and control of HIV and AIDS, to provide for the protection and promotion of public health and for the appropriate treatment, counseling, support and care of persons infected or at risk of HIV and AIDS infection, and for connected purposes.

All these legal instruments and treaties acknowledge that every person has a right to health and to access HIV and other health care services. Incorporating human rights principles into HIV programmes is crucial in order to create an environment where those who are most vulnerable to HIV are able to realize their rights and access the services they need. The people facing these barriers are often the most marginalized, stigmatized and vulnerable to HIV who are mainly women and children. Therefore protecting, promoting, respecting and fulfilling people's human rights is essential ensuring HIV/AIDS infected are able to access to required services and enable an effective response to the epidemic, (UNAIDS,2016).

\section{Criticisms on the Existing Human Rights on Health: HIV/AIDs}

Human rights and public health share the common goal of promoting and protecting the well-being of all individuals as it had been recognized since the first global AIDS strategy was developed in 1987 that Human rights are fundamental to any response to HIV/AIDS. The promotion and protection of human rights are necessary to empower individuals and communities to respond to HIV/AIDS, to reduce vulnerability to HIV infection and to lessen the adverse impact of HIV/AIDS on those affected (Roseman et.al 2002).

Roseman et.al further is of the view that the incidence and spread of HIV/AIDS are disproportionately high among groups who already suffer from a lack of human rights protection, and experience discrimination. This includes groups that have been marginalized socially, culturally and economically with women and children being more prominent groups. People living with HIV/AIDS (PLWHA) or those affected by it will not seek counseling, testing, treatment and support if this means facing stigma, discrimination, and lack of confidentiality or other negative consequences. Discriminatory measures and other coercive actions drive away the people most in need of services.

In deed the 2010 global report on AIDS epidemic (UNAIDS) agrees with Roseman et.al (2002) that Human rights are inextricably linked with the spread and impact of HIV on individuals and communities around the world. Furthermore the lack of Human rights propels the spread and worsens the impact of the disease, while at the same time HIV undermines human rights realization. The human rights abuses are quite rampant among 
certain groups which, depending on the nature of the epidemic and the prevailing social, legal and economic conditions for example women and children, and particularly those living in poverty.

The UN General Assembly Special Session (UNGASS) on HIV/AIDS in June 2001 made the gender dimensions of the epidemic explicit. Delegates from over 180 countries stressed that gender equality and the empowerment of women are fundamental elements in reducing women's and girls' vulnerability to HIV/AIDS. They committed themselves to "intensify efforts to challenge gender stereotypes and attitudes, and gender inequality in relation to HIV/AIDS, encouraging the active involvement of men and boys. Other International commitments like United Nations Commission on the Status of Women(1946), Global Coalition on Women and AIDS, a new initiative launched by UNAIDS involving activists and other non-state actors, In 2003, Task Force on Women, Girls and HIV/AIDS in Southern Africa (2003), which identified key actions to reduce girls' and women's prevalence rates,2006 UN political declaration on women rights, CEDAW ,Beijing Platform for Action (1995),Millenniums Development goals (2000) and Sustainable Development Goals (2015) and other regional and states legal instruments have done much in promoting the human rights of women infected and affected with HIV but much is yet to be achieved.

These international legal instruments for women's right have focused on Preventing HIV infection among women and adolescent girls focusing particularly on improved access to reproductive health, reducing violence against women, protecting the property and inheritance rights of women and girls, ensuring equal access to care, treatment and support for women and girls, Improving community-based care with a special focus on women and girls, Improving access to female-controlled prevention technologies including the female condom and microbicides, Supporting ongoing efforts towards universal education for girls (UNAIDS,2010).

Despite all these efforts, women still face a lot of human rights abuses that worsens effects of HIV/AIDS as Drimie (2003) noted in HIV/AIDS and land case studies in Lesotho, Kenya and South Africa which revealed that HIV/AIDS seriously impact on a range of land issues as a direct result of very high infection rates in these countries, including different forms of land use, the functioning of land administration systems, land rights of women and orphans as well as the poor generally, and inheritance practices and norms. This indicates the importance of effective land administration systems and of land rights as HIV/AIDS impacts on the terms and conditions on which households and individuals hold, use and transact land. This has a particular resonance for women and children's rights, which, in the context of rural power relations that are themselves coming under increasing pressure from the epidemic, are especially vulnerable to being usurped. Human rights watch (2000) in consensus with Drimie couldn't agree less when they noted that Women in Kenya face a variety of property rights violations including exclusion from inheritance, eviction by in-laws and unequal property right during and after marriage. These violations put women at greater risk of HIV infection and stem from a variety of cultural, legal and social factors. Any laws that Kenya has in place to protect women's property rights defer to religious or customary property laws and so are largely ineffective.

Women sexuality rights have continued to suffer greatly in the era of HIV/AIDS as Oriel (2005) noted that the construction of sexuality as gender-neutral in sexual rights literature conceals how men's demand for sexual pleasure often reinforces the subordination of women and resulting into abuses like violence manifested through rape, sexual coercion, sexual objectification, and prostitution which are recognized as a cross-cultural barrier to effective HIV prevention. It's by challenging the forms of sexuality and sexual pleasure that reinforce masculinity that can make it possible to imagine sexual rights that are based on sexual equality for women. In addition Naylor (2005) points out that impact of violence on women's personal, sexual, social and reproductive lives reduces their autonomy and destroys their sense of personal safety and quality of life. In the context of HIV/AIDS, the issue of sexual violence takes on alarming proportions since violence against women fuels the epidemic and the epidemic exacerbates the impact of violence against women. Likewise, , gender based violence poses a challenge to classic human rights work because it occurs in what have traditionally been considered "private spheres" that is the family and the home rather than involving direct abuse by the state. Many SubSaharan Countries have done little to adequately protect women by contextualizing violence against women as a reproductive rights issue and vice versa, or protecting women by silencing and masculinizing women's realities.

Nyamukapa and Gregson (2005) reported that HIV/AIDS Orphaned females suffer fundamental human's rights abuses despite the legal instruments in place to support them which has them denied opportunity to seek education ,exposed them to early sexual debut hence pregnancies, early marriages, rape and all forms of violence therefore denying them a brighter future. Ng'wena (2003) the Millennium Development goals (2000) set ambitious targets for women's health, including reductions in maternal and child mortality and combating the spread of HIV/AIDS .Fast forward in 2015 Sustainable development goals stressed the need to continue providing health opportunities to Women to combat the spread of HIV/AIDS as a matter of humanity a lot of setbacks have been suffered which have stifled the Human Rights of Women; Governments have not made accessibility to quality health care free for women therefore causing class inequality -therefore the inalienability of basic rights is denied(UDHR,1948).

Moreover, as Cock e.t al (2002) note it, women equally suffered rights abuses confronted with mandatory 
HIV testing without their consent which is product of an uninformed decision taking into account the prevailing circumstances resulting into discrimination and stigma. Increased efforts are required to arrange for couples to be tested together for HIV infection, so that HIV/AIDS can be approached as a disease of the family (for couples) and of the society, not left for the individual to decide as that might expose them to rights abuse. We also wish to emphasize the necessity of handling of HIV/AIDs rights of married women with children as a communal right, since it surpasses the threshold of just an individual but multi-interested and affected party now and for a future. Arguably, testing pregnant women for HIV without informed and voluntary consent violates their rights to autonomy, health and reproductive care and non-discrimination all guaranteed in the Protocol to the African Charter on the Rights of Women (Women's Protocol) in addition to other international and regional human rights instruments (Durojaye,2008). The burden of HIV testing should not only rest on the pregnant woman alone buy also on the male partner - this brings to fore the question of the African Man in the health rights of vulnerable women. Respect for women's human rights should form the fulcrum for any call for routine HIV testing for pregnant women in Africa.

Women have continued to suffer due to health care policies which are not sensitive to their human rights. Patient Initiated testing and Counseling for women has not promoted long-term connection with relevant health services and other than increasing testing with no concrete benefits being accrued by the women being tested. Within health services, significant attention should be given to women informed consent, pre- and posttest counseling, patient confidentiality, referrals and access to appropriate services, as well as reduction of stigma and discrimination. Beyond health services, efforts will be needed to address larger societal, legal, policy and contextual issues (Gruskin et al, 2008).

Legal and policy frameworks are available to support realization of women's human rights but little is being done by all actors concerned. Cabal (2003) acknowledged that during the past decades, legal advocacy has played a critical role in changing the realities of women with HIV/AIDS worldwide. The courts may be an excellent venue for bringing about change, especially where there is a disconnect between international, constitutional, or legislative norms and the reality of women's lives but not able to change the attitudes of the societies to support women. This call for the bottom up approach where the solution come from the society and the women who area affected not policy makers an approach that international non-governmental organizations have adopted well.

\section{Applicable Theoretical Framework}

This study has been centred on two complementing theories that address feminism and vulnerability. The two theories are Feminist Legal Theory (FLT) and Vulnerability Theory (VL). According to Obiora and Perry (2001), Feminist legal theory is a legacy both of the $19^{\text {th }}$ Century campaigns for women's emancipation and of the renaissance of feminist activism in the United States and Western Europe in the 1960s. There is much debate in its definition however, Feminist legal theory is a set of ideas, an activity engaged in by thinkers in and outside academia, and an intellectual and political movement. It can be understood as the manifestation in the legal academia of arrange of efforts to understand the nature of women's subordination especially the ways in which it is rationalized and naturalized and to propose solutions for this subordinate condition. Developments in feminist legal theory emerged through engagement with problems rooted inequalities, experienced by Women in communities at the hands of people, corporations, or the state.

Feminist legal theory have conceptualized Women rights abuses as historical and socially constructed embedded in particular social relations and facilitated by legal patriarchal dominance and control. Liberal feminists emphasize the similarities between men and women as rights-bearing autonomous human beings with equal rights which are an inalienable as provided in Universal declaration of Human Rights (1948). Radical feminists argue that society is premised on relations of male domination and female subordination, and that the very epistemological pre-conditions of law and politics are profoundly gendered and therefore women emancipation is needed and among the product of this call is the Beijing declaration of 1995. Postmodern legal feminists show how identities are constituted through multiple structures and discourses that in various ways overlap, intersect, and contradict each other and therefore affirmative actions are needed to address the rights of Women. Cultural feminists emphasize the differences in experience and perspective between men and women, challenging the reification of instrumental capacities of men and denigration of the affective capacities of women which prefer the connection of the individual self to others and this call for actions which intends to change the societal attitudes at personal, institutional and systems level to support women.

The various strands identified above are not an exhaustive inventory of the competing perspectives in feminist legal thoughts, and each has been criticized for its limitation. For example, the cultural feminist perspective is sharply countered by critics who view it as simply an atavistic, throwback to nineteenth century stereotypes, which reified and naturalized the separate-spheres moralizing that entrenched gender asymmetry. By the same token, the radical view is criticized for presupposing a unique female point-of-view that does not allow for social differentiation. Whatever their drawbacks, it is important to note that these strands are not at all 
mutually exclusive; their overlap is particularly evident in their commitment to make the world better for women by reconstituting legal practices that have excluded, devalued, or undermined women's concerns.

Vulnerability theory is used in this study to explain the how of women exposure and the need for the government and other actors to support them. According to Fireman (2010) all human beings are vulnerable and prone to dependency both chronic and episodic and the state has an obligation to reduce, ameliorate, and compensate for that vulnerability. Fineman's notes that asserts that it is neither just nor reasonable to expect that mere equal treatment will meet individuals' needs in a world in which no one is assured of avoiding injury, illness, or other adverse life events. Further in order to meet its obligation to respond to human vulnerability, the state must provide equal access to the societal institutions, that distribute social goods such as healthcare, employment, and security which is consistent with the original purpose of the state: to respond to human vulnerability.

This theory is relevant in understanding the vulnerability of women which has exposed them to inhumane human rights abuses in society. Women have continually suffered in the hands of irresponsive States that have legitimized and given power to social institutions that increase resilience for male while undermining the resilience of women resulting in male domination and female subordination a position taken by feminist legal theorist.

According to Finemans, further to mere equality, vulnerability thought is capable of advancing substantive equality to Women in a way that traditional approaches to equality cannot by focusing on the universal human condition that alter institutional arrangements that create privilege and perpetuate disadvantage therefore proposing solutions that provision of a safety net that is essential when risks to health, safety, or financial wellbeing materialize women as a matter of justice. The fact that every human being is vulnerable should make it easier for individuals to look after each other in society. However, this theory has been criticized for not explain how to prioritize among vulnerable subjects when allocating limited resources, and may actually make it harder to differentiate between competing needs because it emphasizes the universality of vulnerability.

\section{Impact of HIV/AIDs on the Vulnerable Women and INGO Interventions}

The contributions of international non-governmental organization to development through promoting the rights of women affected and infected with HIV/AIDS have received a lot of attention of researchers with some insight contributed to the issue.

According to a report written by the Open Society Institute (OSI), which documents the impact of HIV on vulnerable groups in Kenya, "many women do not take HIV tests in order to avoid the negative repercussions of AIDS stigmatization for themselves and their children, thus denying themselves critical information about their health." Center for Reproductive Rights and Federation of Women Lawyers Kenya (2008) noted that the risk for women of domestic violence and abandonment when their partners learn they are HIV positive has serious implications on how they approach HIV testing, disclosure of their status, and whether to seek treatment. Furthermore, even if a Kenyan woman is not economically dependent on her husband during marriage, she can often find herself in a more vulnerable and precarious situation at the dissolution of their marriage, with dire economic consequences, (FIDA, 2008).

Repressed Kenyan women traditionally gain access to property through their male relatives and when these relationships end through divorce or the death of a spouse, women face the prospect of abandonment and destitution resulting into potential financial vulnerability of single women in Kenyan society. Further, women living with HIV may choose to forego HIV treatment in order to preserve their marriages and financial security or worse still In order to avoid the "issue of stigma and likelihood of discrimination," which may result into the husband hindering her access to proper HIV treatment for his wife and child (NACC, 2006). Women living with HIV have been denied access to reproductive health services in health centers while some still have been denied the right to make informed sexual decisions or even the opportunity to make informed health choices because of their status (UNDP,2016).

In their early days, INGOs were encouraged to embrace a strong advocacy role alongside their role as service providers and to forge alliances with broader social movements in order to ensure their legitimacy (Drabek 1987). With their strong connection to the grassroots and their quest to find innovative and peoplecentred development alternatives, INGOs emerged as organically-linked actors to social movements pursuing transformative agendas (Bebbington et al 2008). Many came to life as organizations primarily aiming to mobilize communities and/or disadvantaged groups and promote their development through advocacy and empowerment, prioritizing smaller development approaches and focusing on a true transformative agenda, with physical changes and improvements seen as second-order goals below their overarching vision of social change.

Islam (2001), Haq (2005), together with Khoso et al., (2011) argued that International non-governmental organizations are one of the actors playing a significant role in highlighting HIV infected and affected women's issues, campaigning for women's empowerment, health and education, violence against women, honor crimes and biased laws. These organizations also run advocacy campaigns for women's rights and play an effective role 
in policy formation about women. Similarly, Qureshi (2004) reported that INGOs are also involved in providing: Free legal aid to women victims of discriminatory customs, lobbying with political parties for inclusion of issues related to women in their political manifestos, monitoring incidence of domestic violence against women, gender discrimination and women trafficking. Scholars such as, Rowland (1997) and Townsend (1999) agreed that International non-governmental organizations can facilitate women in acquiring empowerment by initiating such projects aimed at promoting the socio-economic rights of women by encourage their participation, acquisition of skills, decision making capacity, and control over resources, but that it is women who need to receive benefits and be empowered.

Imaobong Olsson (2012) in her study of Women's Right Advancement and Protection Alternative (WRAPA) which is a local NGO with support from Oxfam(An International non-governmental organization) in Nigeria revealed that INGOS were promoting development through supporting women initiatives found out that WRAPA was fighting for equal rights in access to healthcare, education, and women, as well as equal participation in the political and decision-making. The study noted Oxfam support enabled WRAPA to come up with programmes and projects like legal aid, counseling, advocacy and other institutional support that have enabled social justice for women in terms of gender equality and empowerment of women in the community to be achieved particularly those infected and affected with HIV/AIDS.

A report from a South African INGO, Mothers 2 Mothers $(\mathrm{m} 2 \mathrm{~m})$ equally has showed that International nongovernmental organization contributes to development through protection of the rights of vulnerable HIV/AIDs infected and affected women. The report revealed that this organization provided an innovative, communitybased education and mentoring programme for HIV-positive pregnant women and new mothers. The programme offered clinical outreaches, education and peer support to overcome social and emotional barriers that keep women from accessing medical care.

Furthermore, mother to mother trained and employed new mothers who have them benefited from services to become "Mentor Mothers." These Mentors were empowered to become a team of facility-based, grassroots caregivers and educators for other HIV-positive mothers and became an increasingly integral element of clinical prevention of mother-to-child transmission care. The Mentors focused medical attention toward a mother's wide spectrum of needs - physiological, psychological, emotional, social and spiritual. They are said to contribute to increased uptake of services for the HIV positive woman and her infant through the first year of life, although there are no published formal evaluations of $\mathrm{m} 2 \mathrm{~m}$.

\section{Research Methodology}

Study adopted mixed method while using systematic sampling techniques to select 114 key informant respondents. The data collection methods included use of personal interviews, in- depth interviews, and key informant interviews. Quantitative and qualitative approaches were used in the study and for data analysis where themes, content analysis, and relevant SPSS tool were employed.

\section{Discussions and Results}

The discussions and results were drawn from; Approaches used by World Vision to promote the rights of HIV/AIDS vulnerable women and Impacts of promoting the rights of the HIV/AIDS vulnerable women. These have been aptly discussed below, the basis being voices from the field and scholarly back discourses that strengthen, critic, and complement the findings.

\section{Approaches used by World Vision to promote the rights of HIV/AIDS vulnerable women.}

According Islam (2001) Haq (2005) with Khoso et al. (2011), INGOs have been protecting the rights of HIV/AIDS through various basic approaches which communities find easy to implement. Furthermore, these human rights approaches which targets economic empowerment, health, education and violence are sensitive to the needs of the beneficiaries, society, culture and existing legal frameworks.

Kenya County HIV profile 2016 pointed out that women particularly with HIV Tinderet Sub-county faced a lot of gender-based violence manifested through, physical abuse, emotional, psychological, rape and denial of access to properties like land. The report went further to report that $76 \%$ of HIV infected and affected women have experienced gender-based violence as a result of their status. According to World Vision end of program report 2016, the most common gender-based violence cases reported were; Physical violence at 57\%, emotional abuse $21 \%$, rape $16 \%$ and denial of access to properties $7 \%$ among others.

This study found out that World Vision promoted the rights of HIV/AIDS vulnerable women through; Educating women on their rights through live shows in vernacular radio stations like Kitwek or Chamgei FM where World Vision officials or any of their representatives could attend and educate listeners on the rights of HIV vulnerable Children .Furthermore, they used training, seminars, workshops and focused group discussions as means of educating people on the rights of women. World Vision created forums where women could discuss issues affecting them through the use of psychosocial support groups where they could get counseling and HIV 
infected and affected women clubs to promote discussion on their rights as one participant reported that,

"These forums allowed me open up and share with fellow women how my rights have been abused and how have managed to seek for help"

The study further noted that World Vision advocated for rights of women through citizen participation approach which embraced use of forums public Barazas (public meetings in the villages), churches, road shows, dialogue with community leaders, use of print media like flyers and brochures to sensitize the locals on the rights of Vulnerable women .Pastors were trained to handle women social issues through the program known us channels of hope models and also Chama cha Wazee (A group of elders) initiatives which provided elders in each village with trainings and relevant information concerning protection of women and gave them the opportunity to meet every month and discuss rights of women and rally the community to support them.

Volunteer Men were enlisted and trained as good will ambassadors to promote the rights of women through a platform known as Voice of Women (VOW). Women Rights Soldiers (WRS) another volunteer group were recruited and empowered to act as the link between World Vision and those abused in the community as the primary contacts person whenever women rights were abused. A primary participant observed; "World Vision has helped women through engaging community leaders and traditional leaders to advocate for their rights and this worked because of the respect the community have for elders." In retrospect, an Area Chief who was a key informant reported that, "World Vision staffs sometimes come to our Barazas and talk to people about protecting rights of HIV infected women and those are also affected and this has worked well".

Olsson (2012) acknowledged the role of INGOs in fighting violence against women without which states cannot achieve much .World Vision assisted HIV/AIDS vulnerable women against gender-based violence by reporting cases of abuse to the administration, provide legal aid for those abused to ensure they get justice, provide rescue for those abused and use of "Voice of Women" and "Women Rights Soldiers" as paralegals to help women whose rights have been abused seek justice.

An interview with health care administrator at Meteitei Sub-County hospital revealed that World Vision followed cases of gender-based violence to the latter which since up to 2015292 cases had been referred and relevant forms sent to the authorities for action. (Source: Key informant interview with Health care administrator).

\section{Impacts of promoting the rights of the HIV/AIDS vulnerable women}

The impacts of these interventions were an increase in the level of awareness on the rights of HIV infected and affected women in the community. Beijing declaration 1995 acknowledged the need to make women be aware of their rights in order to look for them which will be big step in achieving development (Beijing Declaration, 1995).

There were reduced cases of violence against women who are HIV infected and affected as a result of these initiatives. Tinderet Deputy County Commissioner noted that World Vision in partnership with the community from 2010 to 2015 assisted in reporting 319 gender-based violence desks at the police station and all these cases were executed fully and with some compensations for damages made since. A study participant narrated how she was raped after the death of the husband by his in-law and at times he could beat her for refusing to be inherited. She reported this case to World Vision because her family was not helping her much. The matter was taken up by police officer, arrest was made, and suspect was taken to court where he was sentence to 14 years in prison which served as lesson to community in 2011. (Source: Interview with a study participants). This is what Chapter 4 of the Kenyan constitution part 2, sub article 28 and Article 5 of the Universal declaration Human rights (1948) requires that nobody should be subjected to torture or to cruel, inhuman or degrading treatment or punishment as that undermines their dignity. Qureshi (2004) noted that INGOs provided free legal aid to women victims of discriminatory customs, lobbied with authorities for inclusion of issues related to women in their policies, monitoring incidence of domestic violence against women and gender discrimination which have gone a long way to support those living with HIV and also affected by with it.

Through these interventions, stigma and discrimination reportedly reduced as reported by the change in attitude among the community members towards people living with HIV clearly supporting International covenant on economic, social and cultural rights (1966) Article 2,Conventions on the rights of women (1979) Article 2 and the Chapter 4 sub-article 27 of the Kenya Constitution(2010) which discourages discrimination of women in all spheres of life regardless of their health status, race amongst others and giving them equal opportunities with men.

A study participant noted that; "People nowadays come to my kiosk to buy vegetables not like some years ago when they used to say that my Vegetables are infected with HIV and they were not good for consumption. It was bad that I had to close down for some time thanks to World Vision, now I have a shop".

According to The POLICY NGOs both local and international were supporting initiatives that addressed issues of Women property and inheritance rights in the context of the AIDS epidemic, and many provided services for widows because of the incapacity of the government Ongalo et.al (2005). It worth noting that 
through the efforts of World Vision, women knew about their rights to get access to their husband or family inheritance -some reported that they got land title deeds, others were able to demand their share of land from family members, others were able to get access to bank loans using family properties as collateral while other reported that they had ventured into running small businesses which traditionally were a reserve of the males like running shops in this community. A study participant said that; "When I lost my husband my Kinsmen evicted me from my home, took all our inheritance and left with nothing to take care of my five siblings. World Vision helped me get back my livestock and land"

An interview with Sub-County development officer revealed that many of the women were able to get loan and from micro-finance institutions or saving and cooperative societies because of the title deeds or being in possession of assets which they use as collateral. This has really promoted development because many of them can now run businesses, take children to school, hospital and improve their standard of living because of the efforts of World Vision.

International Covenant on Economic, Social and Cultural Right (1966) Article 12, Convention on the Right of Women (1979) article 12, the African Charter on Human and Peoples rights (1981) under article 16 and the Bill of Right of the Kenya Constitution (2010) explain the right to health that women should enjoy and promoting them have the potential to improve development in a country. From the findings of this study, World Vision efforts enabled HIV infected and affected women to make healthy choices decision on such as family planning, sexual partner, delivering at the hospitals and attend ante-natal clinics ,seeking HIV testing and counseling services, use of condoms and access to Anti-retroviral therapy (ART) which improved their quality of life and increased productivity. During the interview a study participant appreciated underscored the benefits of healthy choices thus; "Currently am using family planning and this has enabled me to stop giving birth to many children and I also have time to do business and farming instead of constantly taking care of young babies because I understand the benefits".

Beijing declaration (1995) noted that it is essential to design, implement and monitor, with the full participation of women, effective, efficient and mutually reinforcing gender-sensitive policies and programmes, including development policies and programmes, at all levels that will foster the empowerment and advancement of women with preservation of their rights; The participation and contribution of all actors of civil society, particularly Women's groups and networks and other non-governmental organizations and community-based organizations, with full respect for their autonomy, in cooperation with Governments, are important to the effective implementation and development. World Vision activities in supporting women's right have clearly demonstrated the role of INGOs as development agents and gap stopper in situations where the governments failed to address the needs of the citizen. Furthermore, states need other actors like INGOs to accelerate development at the grassroots through structured partnership as demonstrated by Transnationalism theory.

\section{Summary of Findings}

The paper found that there is need to promote rights of HIV/AIDS vulnerable women through approaches such as; educating them on their rights, creating forums for discussing issues affecting them, advocating their welfare, and protecting them from gender-based violence.

\section{Conclusions and Recommendations}

Women rights are basic human rights: civil, political, economic, social, cultural, environmental, developmental, and sexual; and as such are integral to development. From these, it can be concluded that;

i. It is inequalities between women and men that are driving the global HIV \& AIDS pandemic,

ii. In Kenya women accounted for more than $56 \%$ of people living with HIV,

iii. INGOs like World Vision have been supporting implementation of various approaches to promote the rights of women infected and affected with HIV,

iv. The UDHRs clearly stipulates that human rights apply to all equally "without distinction of any kind,

v. Women's rights are protected under international law, and

vi. Human rights on the basis of all instruments do not segregate rights on grounds of sickness; rights remain rights as long as one is human.

It is finally concluded that INGOs such as World Vision have played a significant role in promoting the rights of the vulnerable such as women through community led approaches which are easy to implement with better outcomes.

The study recommends that Human rights education and information should be cascaded down to villages and community members should be allowed to own the process and even monitor and evaluate the implementation of the rights and policies for meaningful gain to be achieved. Government should complement the efforts of INGOS. Therefore, there is need of governmental conscious follow ups after the end of the projects. 


\section{References}

Ahmed, A,. Hanssens, C,. \& Kelly, B. (2009). Protecting HIV positive women's human rights: recommendations for the United States National HIV/AIDS Strategy, Reproductive Health Matters, 17:34, 127-134, DOI: 10.1016/S0968-8080(09) 34464-X.

Altman, D. (1999). Globalization, Political, Economy, and HIV/AIDS." Theory and Society 28: 559-84.

Barnett, T. and Whiteside, A. (2002). AIDS in the Twenty-First Century: Disease and Globalization. Palgrave publishers.

Bebbington, A. J., Hickey ,S,. \& Mitlin,D. (2008). 'Introduction: can NGOs make a difference? The challenge of development alternatives', in: A. J. Bebbington, S. Hickey, and D. C. (eds.), Can NGOs Make a Difference? The Challenge of Development Alternatives, London: Zed Books, pp.3-37.

Bunch, C., \& Frost, S.(2000). Global Women's Issues and Knowledge. Published in Routledge.

Center for Reproductive Rights and Federation of Women Lawyers Kenya (2008). Rights Violation of HIVPositive at risk Women in Kenyan health facilities.

Cock, K. et al. (2002). Shadow on the Continent: Public Health and HIV/AIDS in Africa in the 21st Century 360 Lancet 67.

Commission on Global Governance (1995).Our Global Neighborhood, pp. 335-357; the quote appears on p. 335. Geneva Switzerland.

Cook, R. (1994). Human Rights of Women: National and International Perspectives. Philadelphia: University of Pennsylvania Press.

Drabek, A. G. (1987). Development alternatives: the challenge for NGOs - an overview of the issues'. World Development 15 (Supplement 1): ix-Xv.

Drimie, S. (2003). HIV/AIDs and Land: Case Studies from Kenya, Lesotho and South Africa. Vol. 20(5). Development Southern Africa, p. 647.

Durojaye, E.(2008). Addressing Human Rights Concerns Raised by Mandatory HIV Testing for Pregnant Women through the Protocol to the African Charter on the Rights of Women, 52(1) Journal of African Law 43.

Edoho, (2008). "Strategic Repositioning of NGOs for Sustainable development in Africa". In Non-Governmental Organizations and sustainable development in Africa, edited by Robert A.Dibie,203223.Lanham,MD:Lexington Books.

Enoch, J. and Piot, P. (2017). Human Rights in the Fourth Decade of the HIV/AIDS Response: An Inspiring Legacy and Urgent Imperative. Health and Human Rights Journals 2017 Dec; 19(2): 117-122.

Fineman, M. A. (2013). Equality, Autonomy, and the Vulnerable Subject in Law \& Politics, in Vulnerability: Reflections on A New Ethical Foundation for Law and Politics. Vol. 13, 22. Ashgate Pub.Co.2013.

Fineman, M. A. (2010). The Vulnerable Subject and the Responsive State. 60 EMORY L.J. 251, 257.

Gauri, V. and Gloppen, S. (2012). Human Rights Based Approaches to Development: Concepts, Evidence, and Policy. World Bank Policy Research, Working Paper 5938, Jan.

Gruskin, S. et al. (2008). Provider-Initiated HIV Testing and Counseling in Health Facilities - What Does This Mean for the Health and Human Rights of Pregnant Women? 8(1) Developing World Bioethics 23.

Haq, F. (2005). Women, Islam and the state in Pakistan, in H, Moghissi (ed.), Women in Islam. Critical concepts in sociology, vol.3, Routledge, London, pp. 198-205.

Hearn, J. (2007). African NGOs: The New Compradors?'’ Development and Change Vol. 38, no. 6: 10951110

Hearn, J. (2002). The 'Invisible' NGO: US Evangelical Missions in Kenya. Journal of Religion in Africa 32, no. $1: 3260$

Hershey, M. (2013). Explaining the non-governmental organization (NGO) boom: the case of HIV/AIDS NGOs in Kenya, Journal of Eastern African Studies, 7:4, 671-690, DOI: 10.1080/17531055.2013.818776.

Human Rights Watch (2003). Double Standards: Women's Property Rights Violations in Kenya. New York: Human Rights Watch.

Human Rights Watch (2007). Hidden in the Mealie Meal: Gender-Based Abuses and Women's HIV Treatment in Zambia. New York: Human Rights Watch.

Ishkanian, A. (2006). From inclusion to exclusion: Armenian NGOs'participation in the PRSP. Journal of International Development, 18(5), 729-740.

Kenya AIDS Strategic Framework 2014/2015 - 2018/2019'[pdf].

Kenya National AIDS Control Council (2006). Assessment of the socio-economic Impact of HIV/AIDS on key sectors in Kenya. City, Country.

Kenya National AIDS Control Council (2014). Kenya AIDS response progress report Progress towards zero. Nairobi, Kenya.

Kenya National AIDS Control Council (2014). 'Kenya AIDS Strategic Framework 2014/2015 2018/2019'.Nairobi, Kenya. 
Kenya National bureau of Statistics and Society for International Development ((2013). Exploring Kenya's inequality: Pulling apart or pulling together? A bridged report. Nairobi, Kenya.

Kenya National Bureau of Statistics (2015).' Kenya Demographic and Health Survey2014.Nairobi, Kenya.

Keohane, R., \& Nye, J., (Eds.). (1971). Transnational relations and world politics. Cambridge, MA: Harvard University Press.

Khoso, I., Shafiq, K., Abdi, A. R., and Shaikih, F. M. (2011). Problems and challenges faced by the rural women: a case study of Baluchistan. Asian Culture and History, vol. 3, no. 1, pp. 158-65.

Korba, P.(2003). State-NGO Relations and Agricultural Sector Development,” in ed. Wisdom J. Tettey, Korbla P. Puplampu and Bruce J. Berman, Critical Perspectives in Politics and Socio-Economic Development in Ghana, (Leiden: Koninklijke Brill NV, 2003): 137.

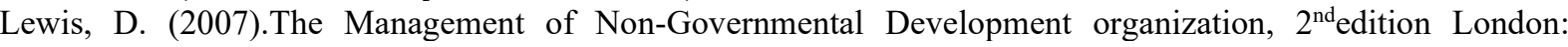
Routledge, pp.290.

Luisa, Cabal et al. (2003). "What Role Can International Litigation Play in the Promotion and Advancement of Reproductive Rights in Latin America?" Health Human Rights 50, Vol. 7(1).

Mann, J. (1999). Human rights and AIDS: the future of the pandemic in health and human rights in 'Health human rights: a reader' .216-226; 1999, New York, NY/London, Routledge.

Mohga, K.S. (2002). World Health: False Hope or New Star in The Global Fund to Fight HIV/AIDS, TB and Malaria $<$ http://www.oxfam.org/ eng/policy paper.

Morsink, J,.(1991).Women's rights in the Universal Declaration. Human Rights Quarterly, vol.13, No. 2 (May 1991).

Mumma, M. C. (2010). Accessing Justice and Protecting the Rights of the Vulnerable through Cultural Structures: A Tool on Working with Elders in Communities. KELIN.

Naylor, N. M. (2005). Cry the Beloved Continent...'Exploring the Impact of HIV/AIDS and Violence on Women's Reproductive and Sexual Rights in Southern Africa. Journal for Juridical Science 52, pp. 52, 55 63.

Ng'wena, C. (2003). Access to Antiretroviral Therapy to Prevent Mother-to-Child Transmission of HIV as a Socio-Economic Right: an Application of s. 27 of the Constitution (2003) 18 SAPR/PL 83.

Nyamukapa, C. \& Gregson, S. (2005). Extended Family's and Women's Roles in Safeguarding Orphans' Education in AIDS- Afflicted Rural Zimbabwe .60(10) Social Science \& Medicine 2155.

Nyong'o, D. \& Ongalo, O. (2005). From Despair to Hope: Women's Right to Own and Inherit Property. Nairobi: POLICY Project and Kenya National Commission on Human Rights.

Obiora, L., \& R. Perry (2001). Feminist Legal Theory in International Encyclopedia of the social behavioral sciences.

Oloo, A. (2007). Governance and Transition Politics in Kenya. University of Nairobi Press.

Olsson, I. (2012). The Roles and Challenges of Non-Governmental Organizations (NGOs) in combating Violence Against Women in Nigeria". A case study of Women's Right Advancement and Protection Alternative (WRAPA).

Oriel, J. (2005). Sexual Pleasure as a Human Right: Harmful or Helpful to Women in the Context of HIV/AIDS? Women's Studies International Forum 392.

Pearce, J. (1997). Between co-option and irrelevance? Latin American NGOs in the 1990s. In D. Hulme\& M. Edwards (Eds.), Too close for comfort? NGOs, states and donors.

Qureshi, S. (2004). Pakistan: Education and gender policy_girls' education: a lifeline to development, Center for Policy Studies, Central European University, Budapest, Hungary.

Rajesh, Tandou (2000). "Riding high or nose diving?" Development in Practice 10 (3): 320.

Roseman, M.J., Gruskin, S., \& Banerjee, G. (2004). HIV/AIDS and Human Rights in a nutshell. Program on International Health and Human Rights François-Xavier Bagnoud Center for Health and Human Rights Harvard School of Public Health 651 Huntington Avenue, 7th Floor Boston, MA 02115 USA.

Rowlands, J. (1997). Questioning empowerment: Working with women in Honduras, Oxfam.

Townsend, J. (1999). 'Power from Within: Getting Out of That House!' in J. Townsend, E. Zapata, J. Rowlands, P. Alberti and M. Mercado (eds.), Women and Power: Fighting Patriarchies and Poverty, pp. 6284. London: Zed Books.

UN Commission on Human Rights Resolutions (2001). 51 of 24 April 2001.New York city,United States.

UNAIDS(2015). How AIDS changed everything: MDG 6: 15 years, 15 lessons of hope from the AIDS response (Geneva: 2015).

UNAIDS (2002). Report on The Global HIV/AIDS Epidemic. Geneva: Switzerland.

UNAIDS (2018). Sustaining the Human Rights Response to HIV/AIDS. Geneva : 2015.

United Nations Children's Fund, Women (2018). At the heart of the HIV response for children, UNICEF, New York, July 2018.

United Nations Development Programme(2016). Accelerating Gender Equality and Women's Empowerment in 
Africa : Africa Human Development Report. New York: 2016.

United Nations High Commissioner for Human Rights and the Joint United Programme on HIV/AIDS (1998). HIV/AIDS and human rights: international guidelines.

UN Doc HR/PUB/98/1 (1998). New York city, United States.

United Nations Human Rights office of the higher Commissioner (2014).Women's Rights are Human Rights. United Nations Publication .ISBN 978-92-1-154206-6 E-ISBN 978-92-1-056789-3.New York and Geneva.

Vienna Declaration and Programme of Action (1993).World Conference on Human Rights. A/CONF.157/24 (Part I), chap. III.

World Health Assembly Resolution (1987). General Assembly resolution 42/8 of 26 October. Geneva Switzerland.

World Health Assembly Resolution (2001). Scaling up the response to HIV/AIDS. Geneva Switzerland.

Yamin, A. E. (2008). "Will we take suffering seriously? Reflections on what applying a human rights framework to health means and why we should care". Health and Human Rights 10, No. 1.

Zweifel, T. (2005). International organizations and democracy. Boulder, CO: Lynne Rienner.

\section{First Author}

Jack Ochieng' Nyaliech is a $\mathrm{PhD}$ candidate of political science at Moi University. He has MA in international relations from the same university. His research interest areas are international political economy, global health and international human rights law. He currently works for WRP (HJF) PEPFAR HIV program in Kenya, and teaches political science at Moi University as a part time lecturer.

\section{Second Author}

Thomas Otieno Juma (DPhil) is a Lecturer of Public Administration at University of Kabianga, Kericho - Kenya. A member of International Political Science Association (IPSA) Global South. An expert in International Relations and Diplomacy with keen focus on Africa. Holds a PhD in Political Science, Kisii University (Kenya), MA in International Relations and Diplomacy, Nkumba University (Uganda), and having started as Bachelor of Business Administration (BBA) student in Bugema University (Uganda), cross-discipline led me to a field that I enjoy most. I have authored many articles centred on; regional security, diplomacy, conflict, governance, and policy in refereed journals in these areas found in open online research depositories. Recently I authored a historical biography "Nyakach Historical Glimpses: A Life of a Century Plus, Hellena Omolo Awich Biograph" published in Nairobi, "Election Management in Regions: A Global Security, now found in Amazon Book stores (paperback and e- Book). Other books are also available online. Initiated a consultancy growing from infancy 'ACIRD - African Centre for International Relations and Diplomacy'. 